\title{
Cannabis for chronic pain: Case series and implications for clinicians
}

\author{
Mark A Ware MBBS MRCP(UK) MSc ${ }^{1}$, Ann Gamsa PhD ${ }^{1}$, Jan Persson MD PhD², \\ Mary-Ann Fitzcharles MD FRCPC ${ }^{1}$
}

MA Ware, A Gamsa, J Persson, M-A Fitzcharles. Cannabis for chronic pain: Case series and implications for clinicians. Pain Res Manage 2002;7(2):95-99.

BACKGROUND: Chronic pain is one of the most common reasons for therapeutic cannabis use.

OBJECTIVES: To describe therapeutic cannabis use among patients with chronic pain.

METHODS: Patients with chronic pain who voluntarily indicated that they used cannabis therapeutically completed a questionnaire about the type of cannabis used, the mode of administration, the amount used and the frequency of use, and their perception of the effectiveness of cannabis on a set of painassociated symptoms and side effects. The study was approved by the McGill University Health Centre Research Ethics Board. RESULTS: Fifteen patients (10 male) were interviewed (median age 49.5 years, range 24 to 68 years). All patients smoked herbal cannabis for therapeutic reasons (median duration of use six years, range two weeks to 37 years).

Seven patients only smoked at night-time (median dose eight puffs, range two to eight puffs), and eight patients used cannabis mainly during the day (median dose three puffs, range two to eight puffs); the median frequency of use was four times per day (range one to 16 times per day).

Twelve patients reported improvement in pain and mood, while 11 reported improvement in sleep. Eight patients reported a 'high'; six denied a 'high'. Tolerance to cannabis was not reported. CONCLUSIONS: The results of this self-selected case series must be interpreted with caution. Small doses of smoked cannabis may improve pain, mood and sleep in some patients with chronic pain. Clinical trials are warranted to test these effects. Further prospective studies should examine the patterns and prevalence of cannabis use among chronic pain populations.

Key Words: Analgesia; Cannabinoids; Cannabis; Pain

Le cannabis contre la douleur chronique : Une série de cas et les répercussions pour les cliniciens

HISTORIQUE : La douleur chronique est l'une des principales causes d'utilisation du cannabis pour des raisons thérapeutiques.

OBJECTIFS : Décrire l'usage du cannabis pour des raisons thérapeutiques chez des patients souffrant de douleur chronique.

Suite à la page suivante

${ }^{1}$ McGill University Health Centre-Montreal General Hospital Pain Centre, Montreal General Hospital, Montreal, Quebec; ${ }^{2}$ Department of Anaesthesia, Huddinge Universitetssjukhus, Stockholm, Sweden

Correspondence and reprints: Dr Mark Ware, Montreal General Hospital, Room D10.137, 1650 Cedar Avenue, Montreal, Quebec H3G 1A4.

Telephone 514-934-2222, fax 514-934-8096, e-mail mark.ware@muhc.mcgill.ca

Received for publication March 5, 2002. Accepted May 15, 2002 
MÉTHODOLOGIE : Des patients souffrant de douleur chronique qui ont volontairement indiqué utiliser du cannabis pour des raisons thérapeutiques ont répondu à un questionnaire sur le type de cannabis utilisé, le mode d'administration, la quantité utilisée et la fréquence d'utilisation, ainsi que sur leur perception de l'efficacité du cannabis sur un ensemble de symptômes et d'effets secondaires associés à la douleur. L'étude a été approuvée par le conseil de recherche déontologique du Centre universitaire de santé McGill.

RÉSULTATS : Quinze patients (10 hommes) ont été interrogés (âge moyen : 49,5 ans, plage de 24 à 68 ans). Tous les patients fumaient du cannabis végétal pour des raisons thérapeutiques (durée moyenne de six ans, plage de deux semaines à 37 ans).

Sept patients ne fumaient que le soir (dose moyenne de huit bouffées, plage de deux à huit bouffées), et huit patients utilisaient le cannabis surtout le jour (dose moyenne de trois bouffées, plage de deux à huit bouffées). La fréquence moyenne d'utilisation correspondait à quatre fois par jour (plage de une à 16 fois par jour).

Douze patients ont fait état d'une diminution de leur douleur et d'une amélioration de leur humeur, tandis que 11 ont déclaré mieux dormir. Huit patients ont affirmé ressentir un état d'euphorie, et six l'ont nié. Aucune tolérance au cannabis n'a été déclarée.

CONCLUSIONS : Les résultats de cette série de cas par autosélection doivent être interprétés avec prudence. De petites doses de cannabis fumé pourraient réduire la douleur et améliorer l'humeur et le sommeil chez certains patients atteints de douleur chronique. Des essais cliniques s'imposent pour vérifier ces effets. Des études prospectives supplémentaires devraient porter sur les schémas et la prévalence d'utilisation de cannabis au sein des populations souffrant de maladie chronique.
$\mathrm{T}$ he use of Cannabis sativa in the treatment of pain has been described in the literature since $3000 \mathrm{BC}$ (1). The recent discovery of specific cannabinoid receptors $(2,3)$ and endogenous cannabinoid ligands $(4,5)$ that play an important role in pain transmission (6) has renewed interest in natural and synthetic cannabinoids as therapeutic agents. This recent scientific activity has occurred in parallel with rising popular support in Canada and elsewhere for the use of herbal cannabis as a medicinal agent (7). Health Canada has issued a call for research into the medicinal uses of cannabis, including the evaluation of smoked cannabis in clinical trials (8).

Dose-response considerations are among the first issues to be considered in designing a study of a new drug in humans. Currently, data on cannabis dose requirements for therapeutic effect are limited to oral preparations of delta9-tetrahydrocannabinol (THC) and cannabis extracts. There are few data on the doses of smoked cannabis used by medicinal users, but such information may be useful in estimating starting doses for clinical trials and for developing other modes of cannabinoid drug delivery.

Chronic pain often involves a complex constellation of symptoms, including pain, anxiety, fatigue, limitation of activity and depression, all of which contribute to a reduced quality of life. Preclinical research provides compelling evidence that cannabinoids exhibit antinociceptive effects in animal models of acute pain and chronic inflammatory and neuropathic pain (9). Oral THC has been found to have some analgesic effect in cancer pain (10). Oral preparations of whole cannabis containing several cannabinoids have been found to reduce opioid requirements in a single patient trial (11). Smoked cannabis has never been studied in a clinical trial of chronic pain, but anecdotal reports of patients who have smoked cannabis for pain relief suggest that the effects are varied, and include relaxation, reduced anxiety, improved sleep and improved concentration (12). The effects of smoked cannabis on chronic pain may, therefore, be more complex than simple analgesia.

We present a case series of 15 patients with chronic pain who reported having used cannabis for symptom relief. The objectives of the study were to determine the main reasons for using cannabis, the dose size and frequency, the desired and adverse effects, and the experience of tolerance to these effects.

\section{PATIENTS AND METHODS}

Patients were recruited from two sites - the McGill Pain Centre and a university-affiliated rheumatology clinic. The McGill Pain Centre is a tertiary referral centre for the multidisciplinary management of chronic pain. The clinic sees over 250 new patients per year and has over 1000 patients on the register. The rheumatology clinic is staffed by three academic rheumatologists and is located about $20 \mathrm{~km}$ from the downtown centre of Montreal. As part of the routine assessment of new patients, patients are asked about the previous use of pain management techniques, including conventional and unconventional therapies, and the degree of benefit or side effects derived from these treatments. They are not asked specifically about cannabis use. Over a six-month period from February to July 2001, 15 patients chose to report cannabis use for symptom management. These patients were invited to participate in the present study. A structured questionnaire was administered in the presence of the primary caregiver. The diagnosis was provided by the primary care giver. Cannabis use was described by the type of material used (herbal, resin, oil) and method of administration (smoked, eaten, tea). A single dose was defined as the number of puffs or joints taken at any discrete point in time, and frequency was defined as the number of such doses per day. A joint was assumed to be equivalent to eight puffs (13). Patients were asked to indicate which symptoms were present and to categorize the perceived effectiveness of cannabis on each symptom (improved, no change, worse). Because some side effects of cannabis use may be considered by patients to be desirable (eg, the 'high' associated with use), they were asked to rate the side effects qualitatively.

For statistical analysis, perceived effectiveness and side effects were handled as ordered categorical variables and assigned rank scores. Correlations between dose (single and 
TABLE 1

Pain syndromes of 15 patients with experience of therapeutic cannabis use

\begin{tabular}{lcl}
\hline Age (years) & Sex & Pain diagnosis \\
\hline 24 & Male & Ankylosing spondylitis \\
35 & Female & Multiple sclerosis \\
36 & Male & Musculoskeletal pain \\
40 & Male & Cervical radiculopathy \\
43 & Male & Fibromyalgia \\
44 & Female & Rheumatoid arthritis \\
46 & Male & Reflex sympathetic dystrophy \\
48 & Male & Phantom limb pain \\
51 & Male & Fibromyalgia \\
51 & Male & Lumbar radiculopathy \\
52 & Male & Seronegative spondyloarthropathy \\
53 & Female & Complex regional pain syndrome \\
58 & Male & Lumbar radiculopathy \\
64 & Female & Chronic pancreatitis \\
68 & Female & Rheumatoid arthritis \\
\hline
\end{tabular}

total daily) and effectiveness or side effect scores were examined by one-way ANOVA using Stata version 6.0 (Stata Corporation, USA).

Approval for the study was obtained from the McGill University Health Centre Research Ethics Board, and all patients provided written informed consent.

\section{RESULTS}

Fifteen patients (10 male) - 10 from the pain centre and five from the rheumatology clinic - participated in the survey. The median age of the participants was 49.5 years (range 24 to 68 years). The chronic pain syndromes are listed in Table 1 . Three patients had spinal radiculopathy (one cervical, two lumbar); two patients had rheumatoid arthritis; two patients had fibromyalgia; two patients had complex regional pain syndrome; and one patient each had phantom limb pain, ankylosing spondylitis, multiple sclerosis, chronic pancreatitis, seronegative spondyloarthropathy and a musculoskeletal pain that was not otherwise specified.

All patients smoked herbal cannabis from the flowering heads of the plant -10 in joints, three in pipes and two in both forms. Additionally, cannabis was eaten by two patients and was taken as a tea by one. The median duration of therapeutic cannabis use was six years (range two weeks to 37 years).

Dose size and frequency exhibited wide variability, and could be divided into two main categories: night-time users, who only smoked at night (seven patients), and daytime users (eight patients), who smoked at intervals during the day and night. The median single dose for nighttime users

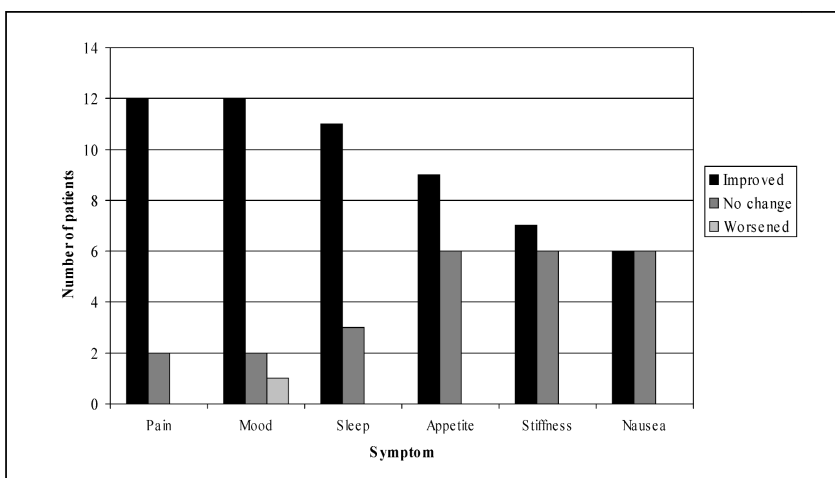

Figure 1) Perceived effectiveness of cannabis on symptoms among 15 patients with chronic pain who used cannabis

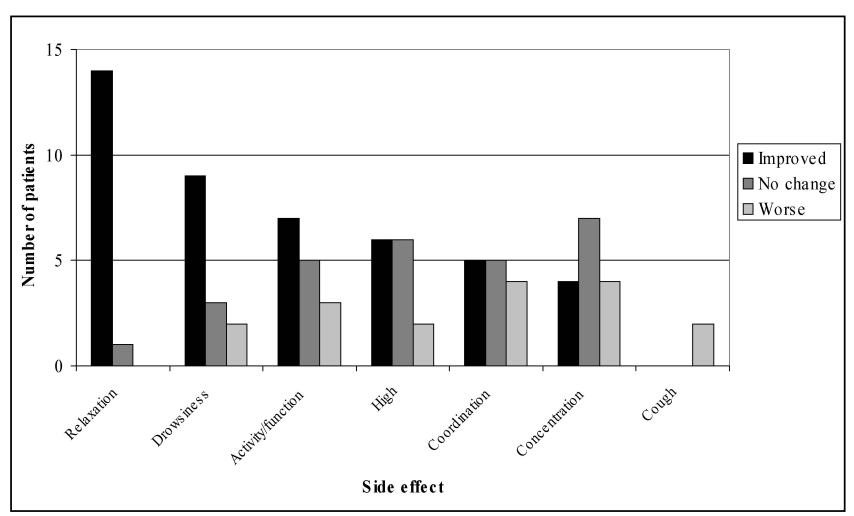

Figure 2) Perception of the side effects of smoked cannabis among 15 patients with chronic pain

was eight puffs (range two to eight puffs). The median single dose for daytime users was three puffs (range two to eight puffs), with a median frequency of four times per day (range one to 16 times per day).

The perceived effectiveness of cannabis on selected symptoms is shown in Figure 1. All 15 patients reported effects on mood (12 reported an improvement, two reported no change and one reported a worsened mood) and appetite (nine reported an improvement and six reported no change). Fourteen patients reported effects on pain (12 reported an improvement and two reported no change) and sleep (11 reported an improvement and three reported no change). Thirteen patients reported effects on stiffness (seven reported an improvement and six reported no change). Twelve patients reported effects on nausea (six reported an improvement and six reported no change).

The experience of side effects of cannabis among the 15 patients is shown in Figure 2. Fifteen patients reported effects on relaxation (14 reported an improvement and one reported no change), change in level of activity (seven reported an improvement, five reported no change and three reported a decrease) and ability to concentrate (four reported an improvement, seven reported no change and four reported a worsening). Fourteen patients reported effects on drowsiness (nine reported an improvement, three 
reported no change and two reported a worsening), 'high (six reported an improvement, six reported no change and two reported a worsening) and coordination (five reported an improvement, five reported no change and four reported a worsening). Two patients reported having a cough.

Neither single nor total daily dose was related to the perceived effectiveness of any of the symptoms. For all patients, 'high' was significantly associated with individual dose size $(\mathrm{F}=18.49, \mathrm{P}=0.001)$ but not with total daily dose $(\mathrm{F}=0.64, \mathrm{P}=0.44)$. After excluding daytime users, the relationship between single dose and 'high' remained significant for the nighttime users $(\mathrm{F}=24.11, \mathrm{P}=0.0044)$.

\section{DISCUSSION}

This survey of 15 patients with chronic pain who reported using cannabis for therapeutic purposes is limited by its small size, inherent self-selection bias and lack of control group and should, therefore, be interpreted with considerable caution. We are cognizant of the fact that our data came mainly from those who had tried cannabis and found it tolerable and effective; only one subject in our case series reported that cannabis use was completely unhelpful and associated with debilitating side effects. Despite these limitations, we believe that our study raises some interesting points.

The first point is that pain relief is only one outcome to be addressed in trials of cannabis or cannabinoids for pain. The patients with chronic pain in this survey reported effects of cannabis on pain, sleep and mood. Some patients also reported that cannabis improved their functional status, and their ability to concentrate and relax. This finding is contrary to reported behavioural changes such as the amotivational syndrome (14) and cognitive impairment (15) in long term recreational users. This paradox has been observed in patients with chronic cancer pain whose responses to morphine in performance tasks were different from those of healthy subjects (16). Pain itself may reduce the ability to concentrate on task performance; therefore, while cannabis may impair concentration in healthy subjects, pain patients might experience a different effect. We also note that the 'high' associated with cannabis use may be perceived as a beneficial effect by patients rather than an undesirable side effect. Therefore, we recommend that, in addition to pain, a range of objective, subjective and functional outcomes including mood, quality of life and sleep should be assessed in both short term and long term studies of cannabis and cannabinoids in chronic pain states.

A second point that arises from this survey is the difficulty in estimating therapeutic dose sizes. In this series, most patients reported using herbal cannabis smoked as a joint, with doses ranging from two puffs at night to several joints per day. There are several potential sources of variability to be considered in estimating doses from such survey data. First, individual patients have different ideas of what constitutes a joint (including size, tobacco admixture and presence of a filter), and may have different puff sizes; the cannabis that they use comes from different sources, which may independently influence the amount of cannabinoid delivered. Second, the type of cannabis preparation used must be considered in deriving dose estimates from such patient data. While cannabis potency is usually measured in terms of THC content, herbal cannabis is known to contain a mixture of other cannabinoids in addition to THC. While THC is the most abundant cannabinoid in drug-type cannabis, nonpsychoactive cannabinoids such as cannabidiol may possess anti-inflammatory, antispasticity and sedative properties that offer potential benefit in disorders such as arthritis (17). Cannabidiol may also modify the anxiety provoked by pure THC administration (18). It is well known that herbal cannabis originating from different geographical regions may contain different profiles of cannabinoids (19), and hashish, the compressed resins synthesized on the flowering heads, may also contain cannabinoid profiles that are different from those of herbal cannabis (20). Thus, the source of the cannabis used by patients may affect not only the dose but also the response. Third, it is not known whether the dose used for therapeutic effect is associated with the severity of pain or with other behavioural or biological factors. Many patients may have had prior experience with cannabis use recreationally (21), which may change their expectation of the drug's effect (22).

Despite this variability, the doses used among the patients in this survey tended to be modest. Some patients used cannabis at a dose of one joint at night, while daytime users smoked fewer puffs more frequently. A total daily dose of one joint per day, either as one dose or in divided doses, appeared to be most common in our patients. The long term effects of this level of exposure to smoked cannabis on the respiratory and other systems are not well known.

In summary, many pain practitioners across Canada will have encountered patients who are either already using cannabis for pain relief or who, in light of recent media interest in medical cannabis issues, will present to their physicians requesting advice or further information. A useful background on cannabinoids has appeared in a previous issue of Pain Research E Management (23). With the belief that some information is better than none, we hope that this series of 15 patients with a variety of pain syndromes who reported their experience of cannabis use for symptom management will be of some use in guiding the sort of questions to ask. Our data suggest that dose sizes may be measured in puffs, and that pain relief is one of several possible outcomes that chronic pain patients are seeking to achieve with cannabis use.

We would like to make three suggestions for further research. First, large, prospective questionnaire studies are required to determine the prevalence of cannabis use among patients with chronic pain, and to ascertain the number of patients who have tried cannabis but not found it useful. Second, more detailed data on the dose (size and frequency), and the perceived benefits and side effects of cannabis use are required. We believe that therapeutic cannabis users are a useful potential source of this information, and we suggest that these data may be collected with 
the help of the Compassion Club community, where thousands of Canadians are currently obtaining cannabis for therapeutic purposes. Third, the cohort of patients using cannabis under the Medical Marijuana Access Regulations offers a unique opportunity to collect prospective dose and outcome data. Once a standardized cannabis material is available to these patients, some of the inherent variability in dose estimates may be minimized.

ACKNOWLEDGEMENTS: The authors wish to thank Bev Rowat for her assistance in administering their survey and to Anneli Vainio for her support in this project. Mark Ware was supported by a stipend from the McGill University Health CentreMontreal General Hospital Pain Centre.

\section{REFERENCES}

1. Wills S. Cannabis use and abuse by man: an historical perspective. In: Brown DT, eds. Cannabis: The Genus Cannabis. Amsterdam: Harwood Academic Publishers, 1998:1-27.

2. Matsuda LA, Lolait SJ, Brownstein MJ, Young AC, Bonner TI Structure of a cannabinoid receptor and functional expression of the cloned cDNA. Nature 1990;346:561-4.

3. Munro S, Thomas KL, Abu-Shaar M. Molecular characterization of a peripheral receptor for cannabinoids. Nature 1993;365:61-5.

4. Devane WA, Hanus L, Breuer A, et al. Isolation and structure of a brain constituent that binds to the cannabinoid receptor. Science 1992;258:1946-9.

5. Martin BR, Mechoulam R, Razdan RK. Discovery and characterization of endogenous cannabinoids. Life Sci 1999;65:573-5.

6. Meng ID, Manning BH, Martin WJ, Fields HL. An analgesia circuit activated by cannabinoids. Nature 1998;395:381-3.

7. Favorable Medical Marijuana Polls 1995-1999. $<$ http://www.norml.org/medical/polls.shtml> (Version current at February 27, 2002)

8. Health Canada. Medical Marijuana Research Plan. $<$ http://www.cihr.ca/funding_opportunities/cihr_funding_pgms/req_for _proposal/rfpmarijuana_e.shtml> (Version current at June 4, 2001)
9. Richardson JD. Cannabinoids modulate pain by multiple mechanisms of action. J Pain 2000;1:2-14.

10. Noyes R Jr, Brunk SF, Avery DAH, Canter AC. The analgesic properties of delta-9-tetrahydrocannabinol and codeine. Clin Pharmacol Ther 1975;18:84-9.

11. Holdcroft A, Smith M, Jacklin A, et al. Pain relief with oral cannabinoids in familial Mediterranean fever. Anaesthesia 1997;52:483-6.

12. Grinspoon L, Bakalar JB. Marihuana, the Forbidden Medicine. New Haven: Yale University Press, 1997.

13. Huestis MA, Henningfield JE, Cone EJ. Blood cannabinoids. I. Absorption of THC and formation of 11-OH-THC and THCCOOH during and after smoking marijuana. J Anal Toxicol 1992;16:276-82.

14. Farnsworth DL. What is the evidence for an amotivational syndrome in cannabis users? Ann NY Acad Sci 1976;282:1.

15. Solowij N. Do cognitive impairments recover following cessation of cannabis use? Life Sci 1995;56:2119-26.

16. Vainio A, Ollila J, Matikainen E, Rosenberg P, Kalso E. Driving ability in cancer patients receiving long-term morphine analgesia. Lancet 1995;346:667-70.

17. Malfait AM, Gallily R, Sumariwalla PF, et al. The nonpsychoactive cannabis constituent cannabidiol is an oral anti-arthritic therapeutic in murine collagen-induced arthritis. Proc Natl Acad Sci USA 2000;97:9561-6.

18. Zuardi AW, Shirakawa I, Finkelfarb E, Karniol IG. Action of cannabidiol on the anxiety and other effects produced by delta 9-THC in normal subjects. Psychopharmacology (Berl) $1982 ; 76: 245-50$

19. Brenneisen R, ElSohly MA. Chromatographic and spectroscopic profiles of Cannabis of different origins: Part I. J Forensic Sci 1988;33:1385-404.

20. Michoulam R, Shvo Y, Hashish I. The structure of cannabidiol. Tetrahedron 1963;19:2073-8.

21. Ogborne AC, Smart RG. Cannabis users in the general Canadian population. Subst Use Misuse 2000;35:301-11.

22. Vogel-Sprott M, Fillmore MT. Expectancy and behavioural effects of socially used drugs. In: Kirsch I, ed. How Expectancies Shape Experience. Washington: American Psychological Association, 1999:215-32.

23. Cannabinoids. Proceedings of the inaugural meeting of the Canadian Consortium for the Investigation of Cannabinoids in Human Therapeutics. May 25-26, 2001 Halifax, Nova Scotia. Pain Res Manage 2001;6:57-112. 


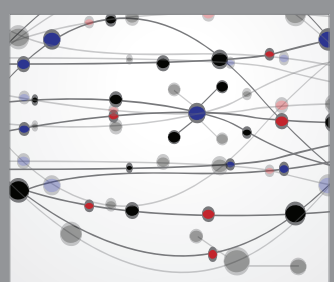

The Scientific World Journal
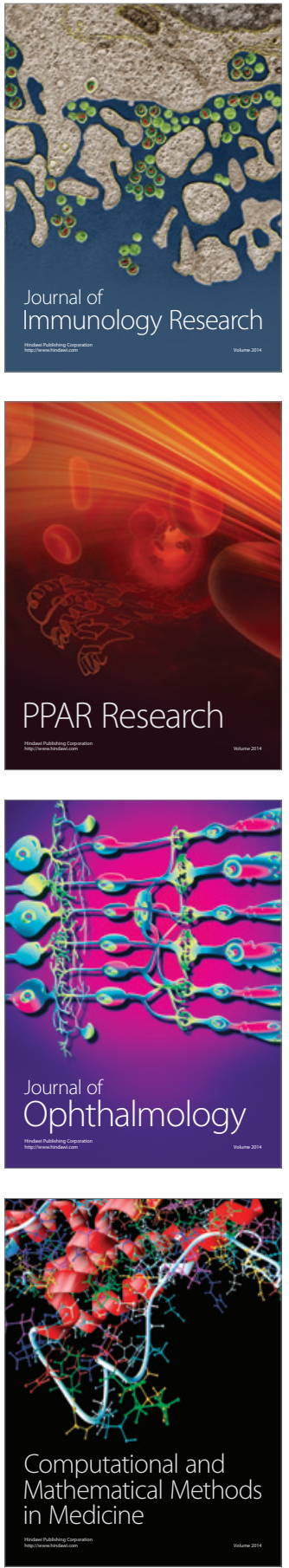

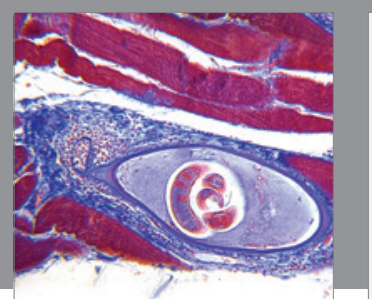

Gastroenterology Research and Practice

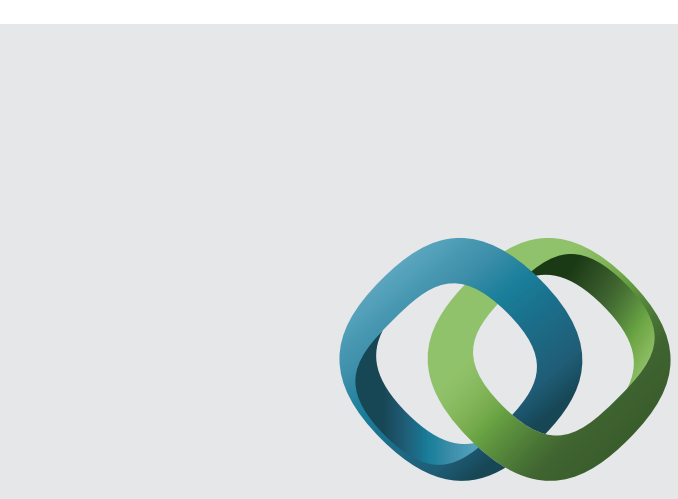

\section{Hindawi}

Submit your manuscripts at

http://www.hindawi.com
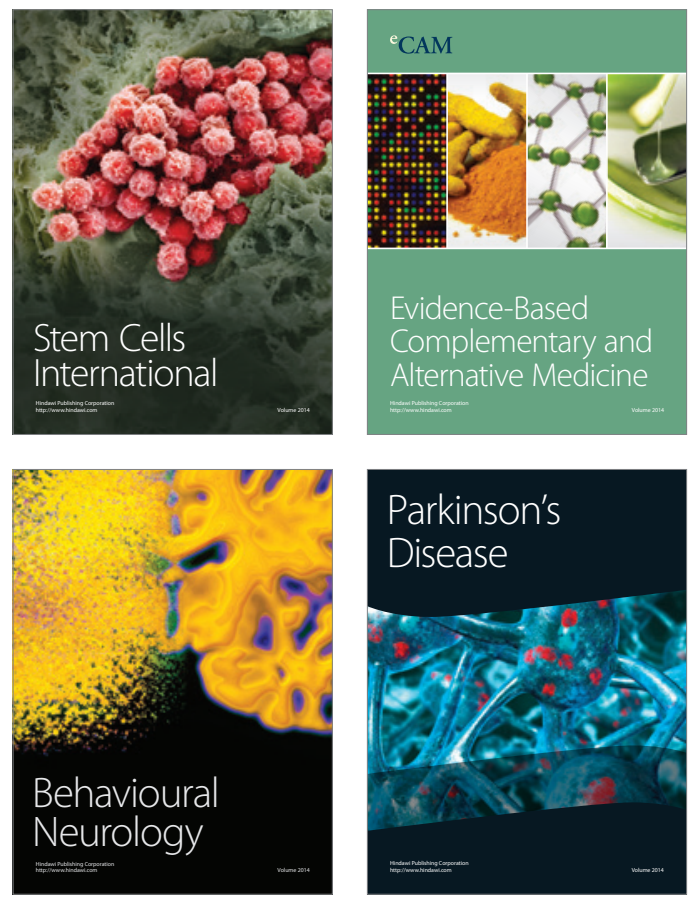
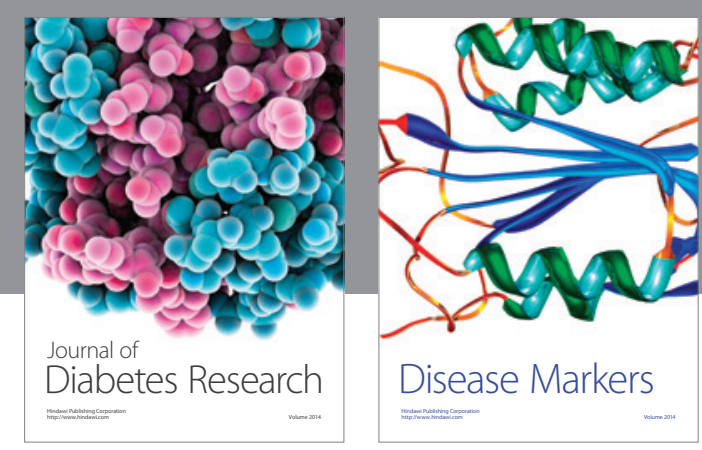

Disease Markers
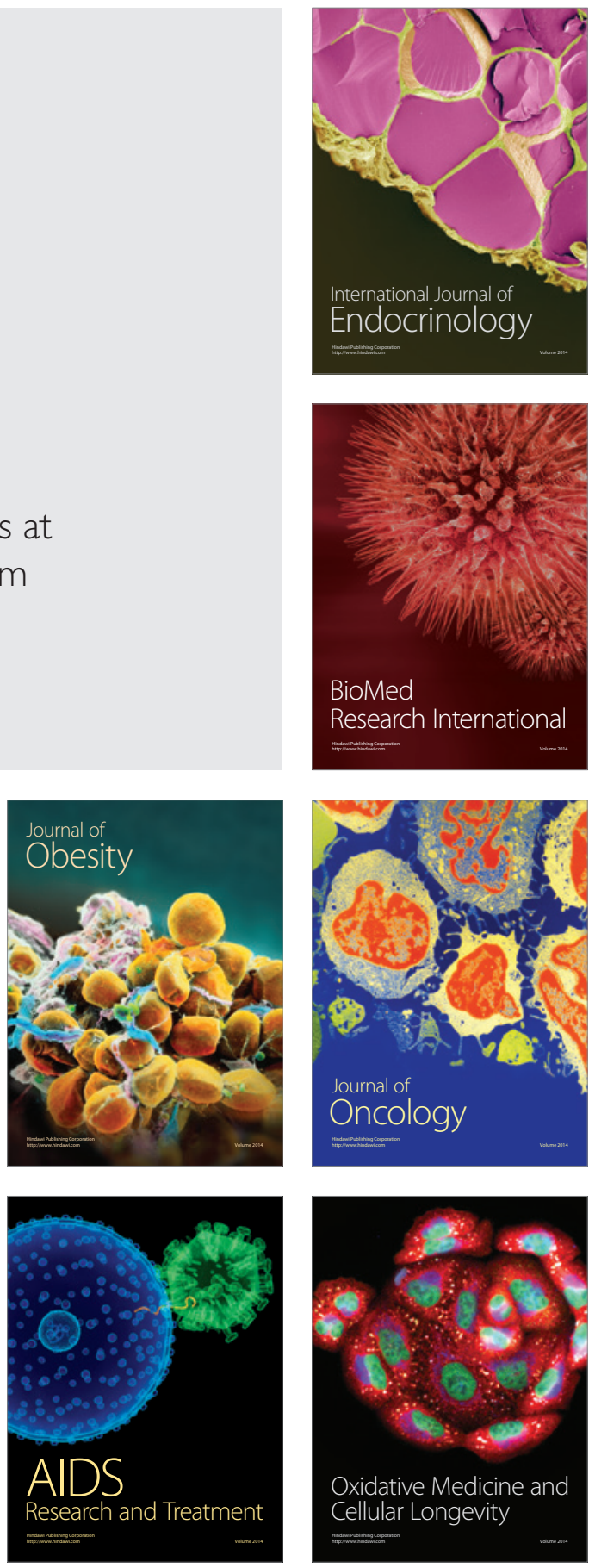